\title{
ENERGY EFFICIENCY ACTIONS RELATED TO THE ROLLOUT OF SMART METERS FOR SMALL CONSUMERS, APPLICATION TO THE AUSTRIAN SYSTEM
}

\author{
Luis Olmos*, Sophia Ruester, Siok-Jen Liong, Jean-Michel Glachant ${ }^{\mathrm{a}}$ \\ ${ }^{a}$ Florence School of Regulation, Robert Schumann Center for Advanced Studies. European University \\ Institute. Via Boccacio 151, I-50133 Florence, Italy.
}

\begin{abstract}
$\operatorname{Abstract}^{\dagger}$
Smart meters (SM) may provide large benefits to all stakeholders by providing the information required to implement certain sets of demand response actions. Benefits produced by SM related actions depend on the features of these actions, the system and the targeted consumer group.

We first lay out an analytical framework to analyse the application of DR actions. Based on this framework, we describe a way to determine the response of domestic load in a system to the implementation of DR actions. We propose determining the overall change in the consumption behavior of domestic load based on previously obtained estimates of the peak load and overall consumption reduction for different types of consumers in different types of systems resulting from the application of each set of actions. We have carried out a comprehensive literature review to provide here such estimates.
\end{abstract}

We then apply the analytical framework and methodology developed to characterize the reaction of consumers in the Austrian system to different SM related actions. Finally, we provide guidelines on which DR actions to implement in this system and how to implement them. The use of advanced indirect feedback on consumption behavior, critical peak prices and simple time-of-use tariffs is advocated.

\section{Keywords}

Smart meters; feedback; time-varying pricing; demand side management; consumer segmentation

\footnotetext{
* Corresponding author: mail: luis.olmos@eui.eu, phone: +39 0554685 869, fax: +39055 4685755.

${ }^{\dagger}$ The research work presented in this article has been carried out in the context of a project funded by the Austrian energy regulator, E-CONTROL.
} 



\section{Introduction}

Directive 2006/32/EC on Energy End-Use Efficiency and Energy Services mandates the installation of smart meters according to a pre-defined agenda for various sectors including electricity and gas distribution. Thus, smart meters are expected to be installed in the coming years in most, if not all, European countries. However, the installation of smart meters should not be analyzed in an isolated way but together with the implementation of different sets of smart-meter enabled actions that are aimed to increase end consumer energy efficiency and that have an impact on the system as a whole. Regulatory intervention is probably necessary to foster the implementation and acceptance of Demand Response (DR) programs worldwide, see [1,2,3].

We analyze different sets of actions that may be directly or indirectly applied upon electricity consumers given a successful rollout of smart meters. Sets of actions related to the use of gas have not been explicitly considered. The potential for increasing the efficiency in the use of gas is limited by the fact that the techno-economic functioning of the gas system is more flexible than that of electricity due to the availability of gas storage capacity. Besides, the use of gas by domestic consumers tends to be far less flexible than that of electricity. In order to increase the efficiency in the use of gas, consumers should be provided with more informative consumption feedback and some relevant advice on efficient practices and equipment.

This report is structured as follows. In Chapter 2, we provide a framework to assess the advisability of the application of smart meter related actions. In Chapter 3, we first discuss how to characterize the reaction of domestic load in a system in which SM related actions are applied based on relevant information on the subject available from pilot projects and modeling exercises. Afterwards, we apply this methodology to determine the impact that the application of different sets of actions would have on the domestic load profile of the Austrian electricity system. In Chapter 4, we discuss the possible implementation of those sets of actions which, according to the previous analysis, would produce the largest benefits for consumers before concluding in Chapter 5 .

\section{Analytical Framework}

Energy efficiency actions taken upon consumers have an effect the functioning of the system which may render some measurable benefits to consumers, both those upon which DR actions are exerted as well as third consumers in the system. Effects and benefits resulting from actions depend on the characteristics of the targeted consumers as well as on the characteristics of the sector and the system where actions are applied (see Figure 1).

Sets of actions to be considered are the provision of feedback to consumers on their electricity consumption (FB), different time-varying pricing arrangements including real-time pricing (RTP), critical peak pricing (CPP), peak time rebates (PTR) and time-of-use tariffs (ToU tariffs), as well as the direct control of consumers' load by third parties (DLC).

Actions can be characterized according to the potential relative advantage that consumers may gain from their application, the complexity of the process of implementing them (representing an extra cost that cannot be easily measured but is affecting the reaction of consumers), and their implementation cost. Potential benefits for consumers from the application of FB and ToU tariffs are medium (advanced FB and ToU) to low (simple FB), while the cost and complexity of their implementation process are low (given a simple tariff structure). Benefits from CPP or PTR are expected to be medium as well. Their complexity is deemed to be low, while their implementation cost is deemed to be medium to low. Finally, RTP and DLC may likely result in high individual and system benefits but the cost of implementation of both sets of actions tends to be high, too. The complexity of their implementation process is medium (RTP) to medium to low (DLC). 
The characteristics of the action itself, those of the system where the action is to be implemented, and those of the targeted consumers jointly determine the actual benefits that consumers will get from the implementation of an action. Consumers can be characterized based on their attitude towards the application of new actions. Thus, active consumers are willing to embrace new energy efficiency actions whereas passive consumers tend to resist their implementation. In addition, one can also classify consumers according to the pattern of electricity usage they exhibit, thus distinguishing between those consumers whose electricity consumption is flexible and can, therefore, be actively managed and those whose load is inflexible. Supply conditions in a system where smart meter related actions are to be implemented may be highly variable, resulting in volatile electricity prices that consumers can arbitrage, or quite stable, implying that consumers would not profit from shifting their load from peak to off-peak hours.

Actual benefits produced by actions together with their implementation costs should guide the final decision on which actions to apply. Some of the benefits for the system and consumers would already be realized immediately after the application of actions, while others would only be realized in the long term. Possible benefits of SM related actions include 1) a decrease in the cost of electricity supply (and therefore in the bill to be paid by consumers) associated with the use of less expensive generation capacity (already in the short term), the reduction in the amount of new generation capacity to be installed (only in the long term) and the decrease in electricity consumption (already in the short term); 2) a decrease in the amount of overall greenhouse gas emissions (starting in the short term and increasing with the passing of time); 3) a decrease in the number and time duration of electricity supply interruptions (already occurring in the short term); 4) a decrease in metering costs and 5) an increase in the self awareness of electricity consumption by households (also developing with the passing of time, but already existing in the short term). The size of benefits realized will depend, not only on SM related actions implemented and the features of the system and consumers, but also on other habilitating policies, like those discussed in [1] for the integration of responsive demand in wholesale markets.

Based on the previous discussion and assessment of the considered sets of actions, one can provide conceptual recommendations on the sets of actions to be implemented depending on consumer, sector, and system characteristics. Ambitious, cost expensive and probably complex actions should be exerted upon active consumers who may greatly benefit from the efficient management of their load. Less ambitious, cheaper and simpler sets of actions should be exerted upon consumers that are active but may probably not get significant benefits from the application of these actions as well as upon passive consumers that should greatly benefit from their application. Finally, no set of actions might be effective in changing the electricity consumption behavior of passive consumers who would only obtain modest benefits from embracing them (see Table 1).

\section{Quantitative Assessment of the Benefits of Smart Meter Related Sets of Actions}

The following discussion focuses on the quantitative assessment of the impact of different sets of smart meter related actions on household electricity consumption. Our aim is to assess the effect that each set of actions is expected to have on households' load profiles. Sets of actions considered in our analysis include a simple package of feedback (more frequent and informative billing), an advanced package of feedback (simple package + comparative feedback + in-home display + personalized energy saving advice); real-time pricing (RTP); simple two-level time-of-use tariffs (ToU tariffs); critical peak pricing (CPP); peak time rebates (PTR) and direct load control (DLC). For a detailed description of the characteristics of these sets of actions see [4]. In section 3.1 we describe the methodology followed to estimate the impact that any action may have on domestic load behavior while in section 3.2 we apply it to the case of the Austrian system. 


\subsection{Methodology}

This paragraph provides a description of the general methodology applied to compute the impact that the application of SM related actions may have on electricity consumption. For the shake of simplicity, we have characterized changes to consumption behavior caused by the application of actions according to the resulting reduction in households' peak load and the decrease in their overall electricity use. This is consistent with the fact that any reaction from consumers to an external stimulus to alter their behavior can be decomposed into a reduction in their overall consumption level and a shift of load from those hours with high prices to those with low prices:

$\rightarrow$ Reductions in the overall level of consumption may be caused by an increase in the overall level of prices, which cannot be justified assuming that original prices are able to cover electricity supply costs; by a reduction in the transaction costs of the implementation of energy efficiency actions, which may correspond to a decrease in the cost of searching for information on the impact that domestic consumer actions have on their expenses or comfort; or by transaction costs associated with the shift of load from some hours to others combined with incentives to carry out this shift.

$\rightarrow$ Load shifts from high to low price hours are deemed to be triggered by differences in prices among these hours and the corresponding opportunities for arbitrage by consumers between them, which would lead to a reduction in their electricity bill. Therefore, the size of load shifts is deemed to be directly related to the level of price differences between peak and off-peak hours.

Besides being reasonable, characterizing consumers' reaction to DR actions based on the resulting decrease in their peak and overall consumption levels is deemed necessary because, for many of the studies conducted on DR programs, information made publicly available is limited to these two parameters.

As mentioned in section 2, benefits that consumers will get from the application of some SM related actions, and therefore the reaction of consumers to these actions, is determined by i) the characteristics of the action implemented, i.e. the type of time differentiation of electricity prices introduced through this action or the type of information provided to consumers through it; ii) those of the system considered, which will affect the differences among the cost of electricity supply in different hours and, therefore, if pricing system arrangements in place allow supply costs to be transferred to consumers, the price arbitrage opportunities available to the latter; and iii) the type of consumers addressed, which comprises the type of uses they make of electricity and their active/passive attitude towards the implementation of DR actions.

Thus, the impact of DR actions on domestic consumer behavior in a system must necessarily be computed independently for each type of action and consumer:

1) Actions implemented determine whether electricity consumer price differences among different hours are possible and the type of price differences to expect (for example, by defining the number of price periods during the day), as well as the type of information on their consumption that consumers have access to.

2) This, together with system characteristics affecting the volatility of wholesale market prices (including aspects like the variability of overall system demand and generation capacity available and network congestion), determine the profile of electricity prices that domestic consumers face and the information they have access to about these prices and their consumption profile. Wholesale prices in a system may vary throughout the year. Supply and demand conditions in the system may depend on the season considered and the specific day within it. One may distinguish between normal days, where system conditions, and therefore prices, are close to those characteristic of that time of the year, and emergency days, where the supply of electricity is at risk and wholesale prices tend to be much higher than average ones.

3) Finally, domestic consumers, when faced with a certain profile of electricity prices, or certain information on their load profile and unexploited opportunities to reduce their bill, should adapt their 
behavior accordingly to the extent that the flexibility of the uses they make of electricity and their level of acceptance and understanding of the functioning of SM allow them to do.

Applying this tree-step framework, each type of consumer in a certain system can be characterized with respect to its level of responsiveness to incentives provided by various SM related set of DR actions. When estimating the impact of DR sets of actions on consumers' behavior, we have classified actions according to the type of signals, or incentives, they provide. These may be in the form of information on their consumption levels, also called Feedback actions. The types of Feedback considered here are the simple and advanced packages described above. But SM related actions can instead involve the application upon consumers of time-varying prices. Pricing arrangements considered here include static pricing arrangements, like ToU tariffs, and dynamic ones, like RTP, $C P P$ or $P T R$. Finally, we have also considered the possibility that consumers contract the management of their load with a third party that is active in the wholesale market $(D L C)$.

As aforementioned, conditions affecting the impact on the behavior of a consumer of the application of a certain type of SM related set of actions have been classified according to two main dimensions: the degree of variability of system conditions, determining the variability of wholesale prices throughout a day, and the flexibility of consumers' load pattern. We have classified system conditions into i) extremely variable, in those days when an emergency compromising the security of the system occurs; ii) variable, occurring in normal days within systems where both the offer and the demand curve are relatively steep; and iii) stable, occurring in normal days in systems with flat offer and demand curves. We have also argued that the flexibility of the load pattern of each consumer depends on two main factors: the flexibility of the uses he makes of electricity and his attitude towards the adoption of new consumption habits. Uses of electricity have been classified into highly flexible ones, which can change to adapt to existing conditions, and those with a low level of flexibility, or rigid ones. Consumers can be classified into active ones, who promptly react to stimuli provided to change their behavior, and passive ones, who tend to ignore these stimuli or are more difficult to mobilize.

However, information on the attitude of targeted consumers towards most of the DR programs analyzed in the literature is not available. ${ }^{3}$ Thus, for the shake of simplicity, when estimating the reaction of consumers in systems with a similar level of socioeconomic development (like those in OECD countries that analyses surveyed refer to) to the introduction of a DR program, it may be sensible to assume a common attitude of the average consumers towards the adoption of new consumption habits. The attitude (or level of acceptance of consumption changes) of the average consumer in any of these systems may be deemed the same as that exhibited, on average, by consumers targeted in DR studies surveyed that use a modeling approach to estimate the reaction of consumers and those field experiments carried out for a large and highly diverse consumer sample. Thus, unless relevant information is available on the general attitude of consumers in the targeted system towards DR programs and it can be compared to that of the average consumer in other systems, we propose leaving aside consumer attitude considerations when estimating the overall change to domestic load in a large system (country) resulting from the application of SM related sets of actions.

The expected reduction in the peak and average load levels of consumers of a certain type in response to the application of a DR set of actions within a certain type of system can be estimated based on those published for studies concerning consumers and systems of the same type. Thus, we have carried out a scrutiny of publications on DR analyses and experiments conducted in developed countries and synthesized the information provided in these documents in Table 2, for peak load reductions, and Table 3, for daily electricity savings.

Regarding feedback on consumption, our literature review included field experiments, pilot projects and first mass rollouts of smart meters accompanied with feedback measures. The provision

\footnotetext{
${ }^{3}$ Gathering information on the lifestyle, values, social or cultural level and other relevant parameters characterizing the attitude of consumers in different systems (countries) towards DR programs is quite difficult and out of the scope of this paper.
} 
of Feedback on consumption led in the studies consulted to a wide range of electricity saving rates between $1.2 \%$ and $18 \% .{ }^{4}$ Differences in savings achieved were associated with those in consumer and system characteristics (heating fuel, appliances, demographic and psychological variables, weather in the area, etc.) as well as with differences in the concrete feedback design. Estimates provided in Table 3 show that more frequent and informative billing including historical consumption (simple feedback package) tends to result in modest consumption reductions clearly below the $5 \%$ level, see $[6,7,89]$. However, feedback accompanied by additional measures such as energy saving advice, pre-payment options, disaggregated feedback and goal setting (advanced feedback package) results in higher savings (about $8 \%$ on average). The latter results are based on the studies in $[10,11,12,13,14,15,16$, 17].

Feedback schemes are not aimed at producing a shift in the use of electricity but at increasing energy efficiency leading to reductions in overall electricity consumption. Thus, most studies consulted do not provide specific information on peak load reductions achieved. Hence, we have assumed that the level of peak load reductions achieved through feedback schemes is the same as that of overall electricity savings, see Table 2. Besides, peak load and overall consumption changes triggered by feedback have been deemed to be the same for normal and emergency days, since economic incentives provided to consumers to change their behavior do not depend on actual system conditions on each day.

Regarding the application of time-varying pricing arrangements, the literature consulted provides a wide range of values for peak load reductions achieved. Differences in values provided are associated with i) the type and size of the consumer sample, including typical end uses of electricity by the different types of consumers considered in each study; ii) the type of system, which, as already explained, mainly has an impact on electricity price variability; and iii) the type of measures applied in combination with pricing arrangements. Regarding the latter, [16] have documented an increase in the effectiveness of ToU tariffs when applied in conjunction with In House Displays providing direct feedback on consumption.

Estimates of peak load reduction levels vary between 3 and $40 \%$ depending on the specific set of actions considered. As Table 2 shows, the largest peak load reductions in normal days are achieved through RTP. An analytical approach to compute the benefits of RTP is used in $[18,19,20]$. CPP seems to be most effective in critical (emergency) days where supply conditions are especially tight. This price arrangement is discussed analytically in $[20,21]$. Other dynamic pricing arrangements also lead to significant peak load reductions in critical days, since they provide strong incentives for consumers to reduce their load in the form of very high final electricity prices. On the other hand, peak load reductions achieved through the application of ToU tariffs in critical days tend to be low. These have been deemed to be the same as those achieved in normal days, since, under this scheme, the stimulus received by consumers to manage their load are not dependent on actual system conditions. Benefits produced by this pricing arrangement are discussed by $[19,22,21]$ also with the help of analytical models. Finally, [23] provides a review of a wide variety of empirical studies on the application of different electricity pricing arrangements. PTR is similar in their conception to CPP. However, as described in Table 2, peak load reductions achieved in critical days through the former are more modest than under the latter due to the fact that economic incentives within PTR come in the form of an extra payment (reduction in the energy bill) associated with load reductions at critical times, instead of severe economic penalties as applied in CPP, which are deemed to be more dissuasive.

Peak load reductions and electricity savings achieved under DLC schemes are conditioned by the fact that their application requires an automation of load management. This is deemed to be only possible for part of the electricity uses of flexible consumers, which consume a large amount of

\footnotetext{
${ }^{4}$ Other reviews of energy saving estimates in the literature provide slightly different ranges for them. Thus, the author in [5] reports savings in studies consulted between $1.1 \%$ and more than $20 \%$, while most estimates are between 5 and $12 \%$ and in a small number of studies no savings are found.
} 
electricity for air/water, heating and cooling. Electricity savings achieved through the application of time varying prices are much lower than those obtained through the provision of feedback, since pricing schemes are mainly focused on triggering load shifts leading to an adaptation of the load to the supply curve (and, therefore, peak load reductions). Thus, only savings in emergency days under dynamic pricing schemes are noticeable: $15 \%$ for DLC, $8 \%$ for RTP, $5 \%$ for CPP and PTR. This is related to the fact that in critical conditions these schemes provide extremely high economic incentives to shift or reduce load, see Table 3.

Once changes to peak and average load levels resulting from the application of a certain set of actions have been estimated for each type of consumer, changes in their daily load profiles can be computed considering two load levels or periods during normal, non-emergency, days (i.e. peak and off-peak), and three load levels in emergency days (i.e. on-peak critical, on-peak non-critical and offpeak). Emergency days are those where emergency conditions, and therefore very high wholesale prices, occur. The remaining days are deemed to be normal days. Changes to the load level of a consumer have been deemed to be homogeneous across all hours within the same load period in a day. The peak load period has been deemed to last all daylight hours, while the off-peak period was deemed to stretch over night.

The following paragraphs mathematically describe the process followed to compute changes to the load profile of consumers corresponding to a certain change in their daily peak and average consumption levels. A distinction is made between emergency and non-emergency or normal days. First, normal days are discussed.

Peak load reductions provided in the literature correspond to a period shorter than a twelve-hours daytime. Hence, for normal days, maximum reductions reported, which correspond to a period lasting only a few hours, have been evenly spread over the entire peak period considered in our modeling. This is mathematically expressed in (1):

$$
\mathrm{UPPR}_{\mathrm{CT}, \mathrm{LA}}=\mathrm{UPLR}_{\mathrm{CT}, \mathrm{LA}} *\left(\mathrm{DPLRP}_{\mathrm{CT}} / \mathrm{DPP}\right)
$$

where UPPR represents the unit peak period reduction for the corresponding consumer and load automation type; UPLR is the unit peak load reduction in per unit terms (parameter estimated based on values published in literature), DPLRP is the duration of the peak load reduction period for the corresponding consumer type and DPP is the duration of the peak period (the number of day hours).

The unit peak period reduction factor for a consumer type, UPPR, must be applied to determine the reduction in his consumption level in peak period hours. The change in the load level over the off-peak period is computed based on the global reduction in electricity consumption computed for the on-peak period and that previously estimated for the whole day. Thus, the change in his consumption level in any hour of the day, RLL, is calculated according to (2) and (3):

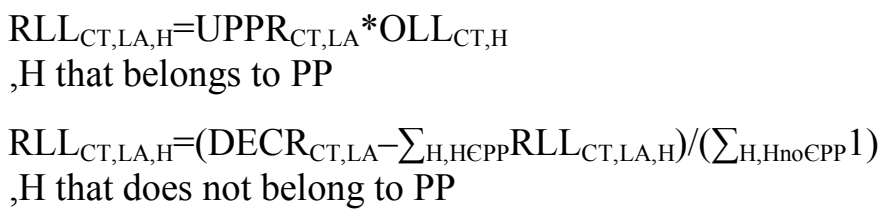

For emergency days, we have made a distinction between prices among i) critical hours (assumed to be always day hours that belong to the critical period), ii) peak (day) hours which are not critical and iii) off-peak (night) hours. Peak load reductions in critical days are deemed to affect only critical hours. In peak non-critical hours, load reductions are deemed to be half of those within critical hours. In off-peak hours load changes are computed based on those occurring in peak hours and the global change in electricity consumption considered for a critical day. Thus reductions in the load level at any hour during a critical day are computed according to equations (4), (5) and (6).

$$
\begin{aligned}
& \mathrm{RLL}_{\mathrm{CT}, \mathrm{LA}, \mathrm{DT}, \mathrm{H}}=\mathrm{UPLR}_{\mathrm{CT}, \mathrm{DT}, \mathrm{LA}}{ }^{*} \mathrm{OLL}_{\mathrm{CT}, \mathrm{H}} \\
& \text {,H that belongs to CP } \\
& \mathrm{RLL}_{\mathrm{CT}, \mathrm{LA}, \mathrm{DT}, \mathrm{H}}=\left(\mathrm{UPLR}_{\mathrm{CT}, \mathrm{DT}, \mathrm{LA}} / 2\right) * \mathrm{OLL}_{\mathrm{CT}, \mathrm{H}}
\end{aligned}
$$


,H that belongs to PP but not to $\mathrm{CP}$

$\mathrm{RLL}_{\mathrm{CT}, \mathrm{LA}, \mathrm{CD}, \mathrm{H}}=\left(\mathrm{DECR}_{\mathrm{CT}, \mathrm{CD}, \mathrm{LA}}-\sum_{\mathrm{H}^{\prime}, \mathrm{H}^{\prime} \in \mathrm{CP}} \mathrm{RLL}_{\mathrm{CT}, \mathrm{LA}, \mathrm{CD}, \mathrm{H}^{\prime-}}\right.$

$\left.-\sum_{\mathrm{H}^{\prime}, \mathrm{H}^{\prime} \in \mathrm{PP}, \text { no€CP }} \mathrm{RLL}_{\mathrm{CT}, \mathrm{LA}, \mathrm{CD}, \mathrm{H}^{\prime}}\right)^{*}\left(\sum_{\mathrm{H}, \mathrm{Hno} \in \mathrm{PP}} 1\right)$

,H that does not belong to PP

As an example, Figure 2 illustrates the modeling we have carried out of the impact of the application of real-time pricing on the daily load profile of a consumer both in normal days (upper part of the figure) and in critical days (lower part). Figure 3 illustrates the more detailed, real impact of RTP on the load curve of a typical consumer.

Using the original and modified load profiles for each consumer type, season and day type, together with the number of consumers of each type in the considered system, one can compute the overall system peak load reduction achieved for each season and day type. As in most studies within the technical literature that have been consulted, we have assumed that major load reductions by consumers are coincident in time with the system peak load (and therefore, the system peak prices for the corresponding day). Finally, taking into account the value of electricity savings rendered by this set of actions for a consumer and day of each type, the number of days of each type in each season and the number of consumers of each type, one can compute the overall system reduction in the electricity consumption over a year resulting from the application of the concerned set of actions.

\subsection{Application of this methodology to the Austrian system}

The methodology described in section 3.1 has been applied to compute the impact of the application of different smart meter related sets of actions on the consumption of electricity by each of the main types of domestic consumers existing in the Austrian system as well as on the overall domestic electricity consumption. Changes to both the peak load level and the overall electricity consumption level have been determined. Subsection 3.2.1 provides the main assumptions made when modeling the behavior of main domestic consumer groups in Austria and the features of the Austrian electricity system. Subsection 3.2.2 provides the results obtained from the analysis.

\subsubsection{Stylized representation of the impact of SM related actions on the Austrian system}

Electricity consumption by main domestic consumer groups in Austria have been modeled using synthetic load profiles produced for each of the main combinations of electricity uses occurring in Austrian households. These combinations of electricity uses correspond to different combinations of consumer and day types. Consumers have been characterized by the level, daily profile and technoeconomic flexibility of their load in each type of day throughout the year (meaning season of the year, namely summer and winter). As argued above, considerations on the attitude of different groups of Austrian consumers towards the change of their consumption habits (differences in their motivations to change their load) have been set aside of the quantitative assessment carried out in this section. Combinations of uses of electricity have been defined in terms of the use of air conditioning and electric heating systems. Load profiles computed consider two load levels (peak and off-peak) in normal days and three in critical or emergency days (critical peak period, non-critical peak period and off-peak). Relevant features of the Austrian system have been modeled through the use of stylized price profiles defined for two types of days: normal and emergency, days.

We have identified five different types of domestic electricity consumers within the Austrian system according to the main uses they make of electricity (five main different combinations of electricity uses have been identified within Austrian households according to the aforementioned criteria). Data on the main uses of electricity in Austria (overall electricity consumption corresponding to this use in each season of the year); the number of domestic consumers in Austria making this use of electricity and wholesale market prices required to produce price profiles for normal and emergency days have been provided by the Austrian energy regulator E-control in the context of a project commissioned to authors of this article. 
Defining the consumption behavior of domestic consumer groups in terms of the use they make of air heating and cooling devices is due to the fact that these electricity uses are deemed to have the largest impact on the load profile of domestic consumers in Austria, see [24]. According to data provided by E-control, about $80 \%$ of consumers ( 2.7 million) have neither electric heating $(\mathrm{EH})$, nor an air conditioning (AC) device at home. Within the remaining households, $60 \%$ employ AC only, $25 \%$ employ conventional $\mathrm{EH}, 8 \%$ use heat pumps and, finally, $7 \%$ have both conventional $\mathrm{EH}$ as well as AC. The amount of electricity consumed by electric heaters is much larger than that consumed by $\mathrm{AC}$ equipment, since summers in Austria are much milder than winters. Within heating devices, heat pumps are, on average, more than twice as energy efficient as conventional equipment. Thus, the average annual electricity consumption of conventional electric heaters was deemed to be $12,000 \mathrm{kWh} / \mathrm{a}$; that of heat pumps $5,000 \mathrm{kWh} / \mathrm{a}$; and that of AC system $1,000 \mathrm{kWh} / \mathrm{a}$. Both AC systems and heat pumps are used mainly during night, while conventional electric heating is used mainly during the day. Based on data and assumptions discussed above, we built a synthetic load profile for each consumer type and season of the year.

In order to define price profiles for different types of days, we used data from wholesale prices at the EEX (German Power exchange) corresponding to the years 2008 and 2009. German and Austrian systems wholesale prices are deemed to be intimately related. These data have also been used to determine the typical number of critical days throughout a year. The number of days in any of these years where electricity prices in the market are well above the average ones was about ten. Average peak load prices in the Austrian system were about $70 € / \mathrm{MWh}$ while the threshold for the identification of outstanding prices was set at $200 € / \mathrm{MWh}$. Using these data, price levels were computed so that the average electricity price to be paid by an Austrian household according to these price profiles and the respective load profiles described above were the same as the one they are paying at the status quo (i.e. the neutrality condition holds). Price levels obtained for a normal day were $0.07 € / \mathrm{kWh}$ for the peak load period and $0.041 € / \mathrm{kWh}$ for off-peak. Price levels obtained for a critical day were $0.11 € / \mathrm{kWh}$ for the non-critical peak period, $0.045 € / \mathrm{kWh}$ for the off-peak period and $0.2 € / \mathrm{kWh}$ for the critical one.

Domestic consumers' responsiveness to price signals or other stimulus to shifting load is deemed to be relatively low compared to that in other countries. This is due to the fact that both heat pumps and AC systems are already used during night (i.e. off-peak times showing lower electricity prices). Conventional EH is used both during day and night time, though more significantly during the day, but shifting its use to the night may have a non-negligible impact on consumers' level of comfort unless the energy efficiency of households is high. Other uses of electricity beyond air heating and cooling are deemed not to be manageable by consumers nowadays. Managing the corresponding devices (fridge, washing machine, etc.) in an energy efficient way would require the installation of smart appliances and their centralized control. One can conclude that the potential in the Austrian system for the shift of load is lower than that in most other systems. Only those consumers with conventional electric heating systems have been deemed to have a high level of flexibility when the use of these devices is automated.

At system level, extreme, or very high, wholesale prices associated with emergency, or close to emergency, situations are deemed to be infrequent due to the abundance of water reservoirs and hydro generating capacity that can be used when supply conditions would otherwise be tight. Existing hydro resources in Austria, together with the fact that the amount of wind generation capacity is small, contribute to reduce the value of controllable load [25]. System prices in normal days have a medium level of variability.

Our analysis of the flexibility of the Austrian system and its domestic load is backed by analyses in [26], where the potential for demand response in different EU countries is assessed using the POLES model [27] to determine load reaction. In [26] both the potential for energy conservation and that for peak load reduction in the considered countries is computed. Table 4 provides these estimates and compares them to the overall size of the country (its overall electricity consumption and generation capacity). It shows that Austria is one of the countries within Europe with a very low potential for peak load reduction achieved through load shifting measures. 


\subsubsection{Numerical results}

This subsection provides numerical results corresponding to the quantitative impact of the considered sets of smart meter related actions on the peak load of Austrian households as well as on their overall electricity consumption level.

Table 5 provides the overall system peak load reduction and overall system electricity savings caused by the application of each of the considered sets of actions to domestic consumers in the Austrian system. Overall annual electricity savings resulting from the implementation of the considered sets of actions are in the range between $14 \mathrm{GWh}$ (for CPP without automation of load) and $1,355 \mathrm{GWh}$ (for the advanced set of feedback), representing more than $7.5 \%$ of total Austrian domestic electricity consumption. Feedback, both in its simple and advanced form, is best suited to achieve significant reductions in the amount of electricity consumed. Simple and advanced feedback packages result in $3.7 \%$ and $7.7 \%$ reductions in total domestic electricity consumption, respectively. Low, but non negligible, electricity savings ranging between 1 and $1.5 \%$ of domestic consumption, can be achieved when implementing time-varying prices in the form of RTP and ToU tariffs, or DLC.

Global peak load reductions achieved in normal summer days are between $60 \mathrm{MW}(3.6 \%$ of the overall system domestic peak load) for simple feedback, and $130 \mathrm{MW}$ (7.6\%) for advanced feedback. In normal winter days, peak load reductions are between $86 \mathrm{MW}(2.8 \%)$ for DLC and $235 \mathrm{MW}(7.7 \%)$ for advanced feedback. Reductions obtained from RTP and ToU tariffs are substantial, ranging between 4.3 and $7.3 \%$ of total domestic load - increasing with the level of load automation. Reductions computed for DLC are lower due to the fact that this measure can only be applied to consumers with standard electric heating when this appliance is used (winter). Peak load reductions achieved in these days from the application of CPP and PTR are zero, since no change in prices is assumed for these actions during normal days.

Peak load reductions in critical days are highest for CPP, RTP and PTR. In summer, they amount to $170 \mathrm{MW}$ or $10 \%$ of the domestic system peak load for RTP and PTR, and up to $200 \mathrm{MW}$, or $12 \%$ of the domestic system peak load, for CPP. In winter, the amount to $10.5 \%$ for RTP and PTR, and up to $550 \mathrm{MW}$, or $18 \%$ of the domestic system peak load, for CPP. Reductions for feedback, ToU tariffs or DLC are between 60 and $130 \mathrm{MW}$ in summer, or 3.6 to $7.6 \%$ of total domestic peak load, and between 110 and $250 \mathrm{MW}$ in winter, or 3.7 to $8.3 \%$ of peak load. Again, DLC results are penalized by the fact that it is only considered for conventional electric heating. One can conclude that peak load reductions achieved in the Austrian system must be considered to be modest for most sets of actions under most circumstances. They tend to increase with the presence of air conditioning or electric heating equipment and with the level of automation of load response. These reductions are highest in critical days for those time-varying pricing arrangements that consider the application of critical or emergency prices.

To summarize, the provision of feedback on electricity consumption, especially in an advanced form, should lead to substantial reductions in the overall use of electricity by Austrian households, whereas the application of time-varying prices and direct load control is expected to result in relatively low electricity savings. Due to the lack of flexibility of the electricity use by Austrian households and the fact that system conditions are deemed to be relatively stable (very low number of emergency situations), peak load reductions achieved through feedback are expected to be at least as large as those rendered by any advanced pricing scheme in normal days. In any case, under tight supply conditions, the application of critical prices would have, by far, the largest impact on the system load.

Results computed implicitly consider the rebound effect on electricity consumption resulting from a decrease in price during certain times of the day (for time varying prices) or the overall decrease in the electricity bill, since a significant number of the studies consulted correspond to field experiments and pilot projects analyzing the actual reaction of consumers. 


\section{Prospective Analysis of the Implementation of Smart Meter Related Sets of Actions}

This chapter focuses on the implementation of those sets of smart meter related actions whose application in Austria seems sensible. If efficiently implemented, these sets of actions should render net benefits for all the relevant parties in the system. A distinction is made between sets of actions whose application is expected to be profitable given the status quo of the system and others that should only be applied if the flexibility of household demand and the variability of prices increase substantially.

\subsection{Preconditions for the implementation of these sets of actions}

In order to achieve the implementation of smart meter related actions, a number of technological and regulatory conditions should be met. First of all, smart meters have to be in place. Their functionality, (such as the minimum set of information to be provided) as well as some basic characteristics of interface hardware and communication protocols should be standardized at system level [26, 28]. The same should apply to the communication and control equipment.

From a regulatory perspective, DSOs, which are supposed to be responsible for the installation and maintenance of all metering infrastructure, should be allowed to recover the cost related to the rollout from consumers. Furthermore, DSOs will have to provide all the relevant information on each customer's actual and historical consumption to the corresponding supplier, which is responsible for billing and therefore also for providing indirect feedback.

Allowing the application of time-varying tariffs to small consumers is another pre-requisite for the adoption of many of the proposed sets of actions. Allowing third parties to develop will be central to the creation of a market for energy services. Finally, some level of firmness of the expected changes to load behavior will be required for demand response to influence major investment and operation decisions by the relevant parties (see also [29]) including i) the level of investments in network assets by DSOs/TSOs, ii) the level of investments in generation capacity, and iii) the level of operational reserves. This may be achieved through a variety of means, including more accurate analyses - by DSOs or suppliers - of load behavior or the arrangement of voluntary contracts between consumers and suppliers or third parties.

\subsection{Common recommendations on the implementation of sets of actions}

Implementing any set of SM related actions requires achieving their acceptance by the parties involved in the process. Here we shall address each of the relevant stakeholders separately, focusing especially on consumers, which are key to the successful application of any measure and currently are far from massively embracing the opportunities created by currently existing DR programs, see [26, 5]. One recommendation that fits all stakeholder groups is the need to achieve a distribution of benefits and costs from SM and related DR programs that is deemed attractive by them [26, 25]. Stakeholders will only embrace new schemes if they can benefit from them. Authors in $[30,31]$ point out that possible causes for the slow pace of implementation of DR in Europe include the publication of unduly high estimates of the cost of DR technologies and the focus of authorities on policies related to the deregulation process of energy systems, some of which may discourage investments in the implementation of DR programs by increasing the investor's exposure to market price risks.

\subsubsection{Engaging consumers}

As $[26,5]$ point out, engaging domestic consumers in DR programs related to the installation of SM may probably be a Herculean task that takes a long time. According to [26], measures may take at least 5-10 years to produce sizable effects at system level. [5] argues that changing consumers' habits regarding the use they make of electricity involves showing them that it is in their hands to do so (they can actually manage their energy use) and that it would greatly benefit them. However, benefits that are relevant to consumers depend on their lifestyle, among other things. Thus, DR actions 
implemented should lead consumers to realize that they will perceive a range of benefits from these actions (cost savings, GHG emissions reductions, adoption of a behavior that is appreciated by others, etc.) some of which may be appealing to them. Communication campaigns about the different potential benefits for consumers and the system of the application of these actions could increase their acceptance and pace of implementation, see [26, 30] for example. These campaigns should also be used to allow consumers to better understand the functioning of Smart Meters and the Demand Response schemes implemented, as well as how to benefit from them. According to [32, 5], the perception that an action is complex and difficult to understand tends to deter consumers from reacting to stimulus provided by it. Consumers' ability to identify the link between changes to their consumption habits and the reaping of benefits increases with the frequency of the provision of information on their consumption or its cost; the level of detail of the breakdown of this information and the persistency in time of the DR actions implemented. Information is also more effective if provided in an understandable and attractive way, probably involving the interaction between the consumer and the system of provision of information [5]. Besides, the amount of information received should not overwhelm the consumer.

In any case, different target (consumer) groups may not only value differently various DR benefits, but also exhibit a different, and generally limited, ability to explore and understand the link between their behavior and benefits obtained. Thus, according to [32], the majority of consumers would prefer to obtain quick, practical recommendations associated with specific changes to their consumption habits and a limited, well designed, amount of information on their consumption (possibly comprising quantities and/or quantities). All in all, [32] and [26] agree that, in order to achieve the engagement of a large amount of domestic consumers in DR programs, a range of products addressing the needs of target groups with different characteristics must be made available. Significant synergies are expected to take place in this case, as consumers that are engaged will tend to look for other ways to save further amounts of energy.

Consumers may probably want to retain privacy of data on their consumption and data security, as highlighted by [25]. However, as [26] point out, this must be made compatible with allowing the access of suppliers and service providers to the data on electricity consumption (consumer load curves properly treated) they need to the design of products to offer their potential customers.

Member States can partially subsidize the installation of metering equipment to encourage consumers to enter the market of DR services, which would force utilities and ESCOS to compete for their customers by offering attractive products, as [33, 32] point out. Apart from this, innovative schemes for the recovery of the costs of smart meter related infrastructure could be used to overcome the opposition of countries and consumers to the installation of this infrastructure [34]. Other options discussed in [26] that can be explored to overcome the initial resistance of consumers and other parties to participate in these programs include: 1) the mandatory installation of SM and implementation of some basic DR actions, or the use of opt-out schemes whereby consumers not willing to participate should explicitly ask not to be included in the default program; 2) the application of yearly limits for the electricity expenses of consumers or; 3 ) the publication of the benefit margin of utilities from DR programs, which would contribute to improve the perception that consumers have of them.

\subsubsection{Engaging other stakeholders}

Regarding the cooperation among states and regions in the application of DR programs, the set of instruments affecting the remuneration of utilities and encouraging them to contribute to the efficient management of the load of their customers (white certificates, market of energy services) should allow the creation of a level playing field for these utilities. Authorities should also make sure that an appropriate scheme for the measurement of changes to the load of consumers resulting from the application of SM related sets of actions proposed is in place.

In order to achieve the involvement of DSOs in the implementation process, their remuneration should not be based on the cost they incur in the provision of system services but should rather be 
linked to the operator's performance compared to some reference. This would encourage them to become more efficient in the provision of these services, probably through their participation in the efficient management of load and the minimization of the life cycle cost of smart meters. Furthermore, the structural characteristics of demand and potentially existing distributed generation should be taken into account when computing the DSOs' remuneration level. This would in turn encourage them to consider demand response and distributed generation in the planning and operation of grids.

\subsection{Sets of actions to be implemented in the short-term}

Sets of actions with the highest potential to render significant benefits to consumers (and the system in general) should be implemented immediately. Some of these actions are aimed at reducing the overall level of electricity consumption (i.e. an advanced set of feedback); others are mainly aimed at achieving a reduction in peak load (i.e. critical peak pricing and time-of-use tariffs). Most of the SM related measures that are expected to have the highest short term potential in Austria have recently started to be implemented within the Austrian system, as reported in [24]. These include an advanced form of feedback and ToU tariffs.

\subsubsection{Advanced feedback}

Advanced indirect feedback should be provided in the form of more frequent (monthly or bimonthly) and more comprehensive information related to consumption available through electronic means. It should include the following information: 1) current consumption and price levels (for the respective billing period as well as the cumulated consumption level for a longer period, such as the current year); 2) historical feedback providing information on the development of own consumption (comparison on a period and year-wise level; corrected for outside temperature); 3) comparative feedback with respect to the consumption level and profile of a suitable benchmark consumer; 4) the environmental impact of electricity consumption (mainly $\mathrm{CO}_{2}$ footprint) and, finally, 5) energy saving advice. Whenever possible, this advice should be adapted to the characteristics of each specific consumer.

\section{Assessment of this set of actions}

In the quantitative analysis of the impact of different sets of actions that we have carried out, feedback has proven to be the most effective option in achieving a reduction in the global use of electricity, as well as in $\mathrm{CO}_{2}$ emissions. Besides, it is expected to result in substantial reductions in peak load levels. Advanced indirect feedback has a significantly higher energy saving potential than simple feedback, which does not include comparative feedback or energy saving advice. The implementation costs of both types of feedback do not differ significantly and tend to be relatively low, except for paper bills when they are necessary. Thus, advanced direct feedback clearly dominates the simple one. The use of direct feedback including real-time, appliance-related consumption data provided by some form of inhome displays is not regarded as a valuable option for its massive application to small-scale consumers (see also [35]). On the one hand, the necessary infrastructure would increase upfront investment costs substantially. On the other hand, the long-term effect of direct continuous feedback is not proven. Therefore, extra investments required to provide this direct feedback are not justified.

\section{Physical means used to provide information}

Information on their use of electricity should be provided to consumers using electronic means as far as possible, including a personalized website managed by the DSO. This is by far the most economical way to reach consumers. Those consumers who do not have access to these means should get paper invoices including all required information on their electricity consumption and energy saving advice. Additionally, a hotline should be made available to provide personalized advice. 


\section{Allocation of responsibilities}

Given that suppliers are selling electricity to consumers and bill them according to their consumption, they should also be responsible for providing feedback when this is done on an individual basis (mainly through any type of bill, but also through hotlines). However, DSOs could also make available some information to consumers using a central platform, like a website. This could include each consumer's load profile and load level, historical and comparative feedback and even some form of personalized energy saving advice. Generally speaking, the implementation of this and other SM related actions will require coordinated actions by different stakeholders in several stages of the supply chain, see [36]. The responsibility or role of different parties in DR programs may vary depending on the specific implementation made of them. Authors in [37] propose several ways to introduce DR economic programs.

\section{Achieving its application}

In order to ensure the involvement of both suppliers and DSOs/TSOs in the provision of feedback to consumers, they should receive extra incentives to achieve a reduction in electricity consumption. Incentives for suppliers could result from a system of white certificates or the development of a market for energy services. White certificates thereby could refer to actual reductions of electricity consumption achieved by consumers. Alternatively, a standard electricity saving capability could be assigned to all the different efficiency actions that can be undertaken [38]. Volume-driven remuneration incentives for suppliers and TSOs/DSOs should be removed.

Consumers could receive extra incentives to reduce their electricity consumption in the form of funds to implement energy efficiency actions including the upgrading of their facilities or homes [39]. Energy audits should be made available by DSOs or suppliers. Finally, the public sector should probably adopt an exemplary role [33]. According to [5], the combination of FB with incentives in the form of personal targets, which can be set through energy audits, or economic incentives through the application of time varying pricing schemes can significantly enhance the level of acceptance of this measure by consumers.

Given that there is strong evidence, backed by the results of our analysis, that the application of advanced feedback should render large net benefits for consumers and the system, and taking into account that there is a mandate by the European Commission to provide feedback, the application of this measure should be made compulsory by authorities. In order to make sure that consumers are able to understand the information provided, its general format should be standardized.

\subsubsection{Critical peak pricing}

Electricity prices must be significantly higher than average prices at times when the reserve margin in the system is below a certain threshold in order to reflect the extra supply costs incurred by the system to serve the load existing at these times. In order to ensure that emergency or critical prices are not applied very frequently, authorities may set a maximum number of emergency hours throughout each year. Critical prices should be set at the average price of electricity during emergency hours (50-100 hours per year). The electricity price should be set at a common level for the remaining hours. This price level, together with emergency prices applied at certain times, should result in an average electricity price that is equal to the one that would have been applied if pricing arrangements had not changed.

\section{Assessment of this set of actions}

Benefits in the short-term from the application of CPP are mainly related to the expected increase in system reliability. In the longer-term, potential savings in generation and network capacity costs due to a reduction in investment requirements could also be substantial. Implementation costs of applying critical prices should not be high. The largest part of total costs would be incurred by the supplier when sending an emergency signal to its customers through a variety of means (website, SMS 
messages, etc.). Given that emergency signals would be sent very few times but showing substantial positive effects on the system reliability and the quality of service, the implementation of CPP is unlikely to face strong opposition.

\section{Physical means used to provide information}

Emergency signals should be sent by electronic means (website, e-mail, SMS messages, etc.). Only when a large number of potential users are not willing or able to use cheaper communication means, the installation of an in-home display should be considered. Related costs would have to be beard by these customers.

\section{Allocation of responsibilities}

Given that suppliers are in charge of computing and applying electricity prices to consumers, they should also be in charge of computing and applying critical prices. In fact, they could be the only party being aware of which of their customers have opted for this pricing scheme. Suppliers hence have to be immediately informed about the occurrence of an emergency situation by the system or market operator.

\section{Achieving its application}

There is no clear mandate from the European Commission to implement time-varying pricing schemes. Besides, evidence suggesting the advisability of their implementation in the Austrian system regarding their short-term impact on electricity savings is not as strong as that found for indirect feedback. However, we believe that implementing CPP or ToU tariffs could increase the efficiency and robustness of the system and will result in significant benefits for all parties. Thus, we suggest that, once the right incentives are in place, the decision on the implementation of these sets of actions is left in the hands of the parties involved in their application (suppliers, TSOs, DSOs and consumers).

Simple time-varying network and capacity charges (if the latter exist), to be initially paid by suppliers, should be applied to encourage suppliers and consumers to reduce the latter's contribution to system peak load at critical times [23]. Default regulated (energy) tariffs for consumers should disappear, since consumers choosing not to enter the market and being subject to these tariffs would not have incentives to shift their load to off-peak times. Apart from this, the remuneration scheme applied to DSOs (mainly) and TSOs (to a lesser extent) should be based on incentives. This would encourage them to facilitate the adaptation of load to system conditions so as to reduce the costs the former incur in providing network-related services. Efficiency incentives for TSOs should supplement and not replace their traditional remuneration scheme.

\subsubsection{Time-of-use tariffs}

If this pricing scheme were to be implemented, different electricity price levels, to be applied at predefined time periods within each day, should be computed well in advance of the operation of the system and updated regularly. Price levels not necessarily have to change between seasons, since prices in the Austrian system are quite stable and short-term supply and demand conditions seem to have a stronger impact on the market price than season-specific weather conditions. The structure of the tariff applied should be kept as simple as possible so as to facilitate the understanding and acceptance of new tariffs by consumers. Thus, defining only two price periods (i.e. a peak period mainly covering day hours and an off-peak period covering night time) would be advisable.

\section{Assessment of this set of actions}

The impact of time-varying prices in the Austrian system may be less significant than that in other countries due to specific supply and demand characteristics. According to our findings, ToU tariffs should prompt some low but non-negligible shift of load from peak to off-peak hours in the Austrian 
system. Modest reductions in global energy consumption may also take place, though much smaller than those from feedback measures.

However, extra implementation costs resulting from the use of ToU tariffs are expected to be almost negligible, especially when combining this tariff scheme with the use of indirect feedback and CPP. Since price levels are determined in advance, consumers face no short-term uncertainty on prices, which should facilitate the implementation of this set of actions.

\section{Physical means used to provide information}

Possible pricing arrangements, including ToU tariffs, should be periodically announced by suppliers using different physical means. Those consumers receiving paper bills should also receive together with them, at least once a year, some information on the possibility of signing in for ToU tariffs. At the same time, electronic means (website or hotline) could also be used to advertise these tariffs. Consumers subject to these tariffs should receive within their bill detailed information on the amount of electricity consumed within each price period together with the respective tariffs.

\section{Allocation of responsibilities}

Suppliers should be responsible for advertising (marketing) newly available tariffs, including ToU tariffs, and billing consumers based on them. Suppliers should be provided by DSOs with relevant information on the amount of electricity consumed by their customers in each of the price periods defined.

\section{Achieving its application}

Conclusions and recommendations to achieve the implementation of ToU tariffs are not significantly different from those applying for CPP.

\subsection{Measures potentially becoming relevant in the longer-term}

The following paragraphs discuss those sets of actions whose application in the Austrian system may be advisable in the longer-term future given the development of exogenous conditions affecting the flexibility of domestic consumers load and that of the Austrian electric system as a whole. Conditions probably necessary for this to happen are discussed in section 4.4.3. Sets of actions considered here are real-time pricing (RTP) and direct load control (DLC).

\subsubsection{Description of these sets of actions}

\section{Real-time pricing}

RTP involves the direct application of prices resulting from the electricity market to households. Electricity prices to be applied shall be those in the day-ahead or the real-time (balancing) markets. As a compromise between the operability of the system and the accuracy of prices applied, these could be hourly differentiated.

Prices applicable at each time should be sent to consumers via an in-house device directly connected to the suppliers' facilities. This could be an advanced smart meter being able to support bidirectional communication.

Suppliers should be in charge of sending real-time prices to consumers as well as advertising these new pricing arrangements to get their customers enrolled on them. They should also be in charge of installing the required communication equipment. 


\section{Direct load control}

DLC involves the provision of advanced energy services associated with space and water conditioning, or even the management of domestic appliances, by a third party. In order to provide these services, this third party would remotely manage the use of electricity in households. Thus, the implementation of DLC requires that the management of load is automated using the corresponding communication and control equipment. Control signals produced by the service provider could be sent through a variety of means including the electric wires (PLC technology) or radio frequency.

Consumers subject to DLC adopt a passive role. The energy service provider would be responsible for controlling part of the in-house electricity consuming equipment in order to provide the contracted services and for installing and maintaining the required communication and control equipment except for that part of the equipment which is already installed as part of the distribution grid, which would remain in the hands of the DSO.

\subsubsection{Assessment of both sets of actions}

Both RTP with a partial automation of load and DLC can produce significant reductions in the cost of operating and expanding the system if the use of electricity by consumers is flexible enough and market prices exhibit large variations. If these conditions are not met, the implementation of these actions at large scale would probably not be profitable.

Implementation costs of both RTP with automation or DLC are very significant. This would include the cost of communication and control equipment necessary to apply them, but also the cost associated with the complexity of their implementation process itself. ${ }^{5}$ Incurring these costs could only be justified if the whole load management potential to be achieved through the application of these sets of actions is realized. Implementing these actions when the number of potential clients for them is small could be uneconomical since a significant part of the equipment required (central data processing and control centers) would probably have to be installed regardless of the number of consumers making use of it.

\subsubsection{Conditions to be met for the implementation of these actions}

The main conditions to be met (all or part of them) to make the implementation of these actions attractive both for suppliers of these services and electricity consumers include the following:

- A significant number of small consumers (households or small businesses) should use air conditioning systems during the day, contrary to what currently occurs in households. Then, RTP and DLC could be used to shift part of this load towards off-peak hours.

- An increase in the flexibility of households' electricity demand should take place, probably as a result of smart appliances being developed and embraced by consumers, as discussed in [25]. Authors in [25] explain that the application of time varying electricity pricing schemes would encourage consumers to buy smart appliances in order to better control their load profile and further reduce their electricity bill.

- System conditions should be far more variable than today, resulting in far more variable electricity prices as well. As discussed in [25], this could be the result of the installation of significant amounts of intermittent renewable generation (mainly wind generation in areas that are not accessible now) together while hydro generation capacity stagnates.

\footnotetext{
5 "RTP is generally considered too complex for small electricity users [...] these types of tariff may become more likely, closer to or post-2020, when continuous automated switching of load could be valuable" [28].
} 


\subsubsection{Achieving the application of these sets of actions}

Both sets of actions - assuming demand is flexible enough and system conditions are variable - could bring significant benefits to all the parties involved in their implementation. Some sort of automation of the response of consumers to dynamic prices would be most advisable under RTP so that it has a high impact on consumers' behavior. Peak load reductions achieved could be substantial, while energy savings obtained if a significant part of the households' electricity use is automated could also be very important.

Communication and control equipment to be installed as a result of the application of RTP or DLC schemes would finally have to be paid by consumers either through the non-regulated tariff or through third party arrangements (paying these investments from the savings in their energy bill they achieve). In order to provide suppliers with some certainty about the recovery of the corresponding investments, contracts between suppliers and consumers should include a compensation to be paid to the supplier if this contract is ended before a certain amount of time has passed after the installation of communication and control equipment. This compensation could be paid by the consumer or the new supplier.

As explained earlier in general terms, the standardization of interface hardware, communication protocols and the functionality of systems would be needed in order to achieve the desired level of interoperability among alternative energy service providers. Other recommendations corresponding to the implementation of indirect feedback or simple time-varying prices apply here as well.

\section{Conclusions}

The implementation of different sets of SM related sets of actions in the residential electricity sector shall be assessed in the light of the specific characteristics of the targeted consumer group and the system where these measures are to be implemented. Relevant characteristics of consumers in this regard include the type of uses they make of electricity determining their load level and flexibility of their consumption profile and their attitude towards a change in consumption habits. Relevant system features are related to the variability of electricity prices. SM related sets of actions can be classified into those mainly focused on achieving a reduction in the overall use of electricity (Feedback) and those focused on modifying the pattern of consumption throughout the day (Time Varying Pricing Arrangements). Specific recommendations have been provided for different types of consumer groups using a simple analytical framework.

According to the framework developed, we have also illustrated a way to estimate changes to domestic load in a system resulting from the application of Smart Meter related actions based on knowledge already existing in the literature. This has been done through the derivation of estimates of the reduction in the peak load and overall electricity consumption of different types of consumers in different types of systems resulting from the application of each type of action. Afterwards, we have applied the methodology developed and estimates derived to determine the impact that the application of several actions would have on domestic load to the Austrian system. Finally, we have derived some principles that should guide the process of implementation of SM related actions. This has been done with a focus on the Austrian system, though principles identified are deemed to be generally valid when adapted to take into account the specific conditions applying in each case.

The engagement of consumers in schemes implemented is central to achieving sizable benefits for them and the system as a whole. This would require increasing the frequency, amount, and detail of consumption information provision while making this information easily understandable and accessible. In order to make the application of SM related actions more successful, the provision of information should be combined with other measures, namely the provision of economic incentives in the form of time varying prices of different kinds, energy saving tips, etc.

Conditions existing in the Austrian system advise applying some form of advanced indirect feedback in order to increase the efficiency in the use of electricity. According to our own estimates, 
electricity savings in this system achieved through the application of advanced feedback could be as high as $8 \%$ of overall consumption. Based on the mandate for the provision of feedback in European legislation, and the strong evidence collected on its electricity saving potential, we recommend that a basic feedback package including historical and comparative feedback, as well as personalized energy saving advice is provided on a compulsory basis by suppliers and DSOs. The format of information provision should be standardized. In order to align suppliers' interests with those of the system, regarding the application of feedback, inefficient volume-driven incentives faced by these parties should be replaced with efficiency-driven incentives in the form of a white certificates system or a market for energy services. DSOs/TSOs' remuneration schemes should include some efficiency incentives and should take into account the specific situation existing in each area regarding the penetration of distributed generation and load management practices.

Furthermore, the application of critical peak prices and simple time-of-use tariffs should also be considered in the short-term. This should result in peak load reductions during normal days amounting to 4 to $8 \%$ of global system residential peak load in Austria. Reductions thereby are proportional to the level of load automation. Peak load reductions in critical days achieved through the application of CPP would range between 10 and $16 \%$. This is expected to result in a significant increase in system reliability and significant long-term savings due to the avoidance of generation and network capacity investments. The decision on the application of CPP or ToU tariffs should be left in the hands of suppliers, who should be provided with efficiency-driven incentives in the form of cost reflective timevarying network charges reflecting the true system cost of the use of the network by agents. Capacity charges, if they are to be applied in the Austrian system, should also be of a time-varying nature. Implementing an efficiency-driven remuneration scheme for DSOs and TSOs would also be necessary.

Finally, if the domestic load in the Austrian system became more flexible, or the volatility of electricity prices increased, implementing a scheme of real-time prices or the direct control of consumers' load by third parties could be advisable despite the high implementation costs of these sets of actions. Incentives to be sent to relevant parties (mainly suppliers and service providers) to decide on the application of these sets of actions would be those already discussed for ToU tariffs and CPP.

\section{Acknowledgements}

The analysis presented in this article has been carried out in the context of a project commissioned by the Austrian energy regulator E-Control. For a detailed discussion on the topic, please consult the project report [4].

\section{References}

[1] Centolella, P. The integration of Price Responsive Deamnd into Regional Transmission Organization (RTO) wholesale power markets and system operations. Energy 2010; 35(4); 15681574.

[2] Zarnikau, J.W. Demand participation in the restructured Electric Reliability Council of Texas market. Energy 2010; 35(4); 1536-1543.

[3] Walawalkar, R, Fernands, S, Thakur, N, Chevva, K.R. Evolution and current status of demand response (DR) in electricity markets: Insights from PJM and NYISO. Energy 2010; 35(4); 15531560.

[4] Olmos, L, Ruester, S, Liong, S.J. Energy Efficiency Actions Related to the Rollout of Smart Meters for Small Consumers. A report by the Florence School of Regulation for E-control, 2010.

[5] Fischer, C. Feedback on household electricity consumption: a tool for saving energy? Energy Efficiency 2008; 1(1); 79-104. 
[6] Seligman C, Darley J.M. Feedback as a Means of Decreasing Residential Energy Consumption. Journal of Applied Psychology 1977; 62: 363-368.

[7] Midden CJH, Meter JF, Weenig MH, Zieverink HJA. Using Feedback, Reinforcement and Information to Reduce Energy Consumption in Households: A Field-Experiment. Journal of Economic Psychology 1983; 3:65-86.

[8] Houwelingen JHv, Raaij WFv. The Effect of Goal-Setting and Daily Electronic Feedback on InHome Energy Use. Journal of Consumer Research 1989; 16:98-105.

[9] Matsukawa I. The Benefits of Information on the Efficient Usage of Consumer Durables: Experimental Evidence Concerning Residential Energy Conservation. Musashi University Discussion Paper No. 38; 2004. Available from: http://129.3.20.41/eps/othr/papers/0501/ 0501005.pdf.

[10] Dobson JK, Griffin JDA. Conservation Effect of Immediate Electricity Cost Feedback on Residential Consumption Behavior. Proceedings of the 7th ACEEE Summer Study on Energy Efficiency in Buildings, Washington, DC; 1992.

[11] Wilhite H, Ling R. Measured Energy Savings from a more Informative Energy Bill. Energy and Buildings 1995; 22:145-155.

[12] McCalley LT, Midden CJH. Energy Conservation through Product-Integrated Feedback: The Roles of Goal-Setting and Social Orientation. Journal of Economic Psychology 2002; 23:589-603.

[13] Karbo P, Larson TF. Use of Online Measurement Data for Electricity Savings in Denmark. ECEEE 2005 Summer Study - What works and who delivers?; 2005. Available from: $\mathrm{http}: / /$ www.eceee.org/conference_proceedings/eceee/2005c/Panel_1/1180karbo/.

[14] Ueno T, Sano F, Saeki O, Tsuji K. Effectiveness of an Energy-Consumption Information System on Energy Savings in Residential Houses Based on Monitored Data. Applied Energy 2006; 83:166-183.

[15] Abrahamse W, Steg L, Vlek C, Rothengatter T. The Effect of Tailored Information, Goal Setting, and Tailored Feedback on Household Energy Use, Energy-Related Behaviors, and Behavioral Antecedents. Journal of Environmental Psychology 2007; 27:265-276.

[16] Faruqui, M, Sergici, S, Sharif, A. The impact of informational feedback on energy consumptionA survey of the experimental evidence. Energy 2010; 35(4); 1598-1608.

[17] Togeby M. Energy Efficiency and Demand Response - Results from two Danish Experiments for Households with Smart Meters. ESMA \& JRC Workshop on Smart Metering, 16-17 February 2010, Gazzada Schianno-Varese, Italy.

[18] Allcott H. Real-time Pricing and Electricity Markets. Harvard University Working Paper; 2008; Available from: http://citeseerx.ist.psu.edu/viewdoc/download?doi=10.1.1.151.6305\&rep=rep1\& type $=$ pdf.

[19] Borenstein S. The Long-run Efficiency of Real-time Electricity Pricing. Energy Journal 2005; 26:93-116.

[20] Violette D, Freeman R, Neil C. Valuation and Market Analyses. Volume II: Assessing the DRR benefits and costs. International Energy Agency, Demand Side Programme; 2006. Available from: http://www.demandresponsecommittee.org/Analysis\%20of\%20Valuation $\% 20 \mathrm{of} \% 20$ Demand $\% 20 \mathrm{R}$ esponse $\% 20$ Volume $\% 20$ II.doc.

[21] Faruqui A, George SS. The Value of Dynamic Pricing in Mass Markets. The Electricity Journal $2002 ; 15: 45-55$.

[22] Commission for Energy Regulation. Demand Side Management \& Smart Metering. Consultation Paper CER/07/038; 2007.

[23] Faruqui A, Harris D, Hledik R. Unlocking the $€ 53$ Billion Savings from Smart Meters in the EU How Increasing the Adoption of Dynamic Tariffs Could Make or Break the EU's Smart Grid 
Investment. The Brattle Group Working Paper; 2009. Available from: www.brattle.com/documents /uploadlibrary/upload805.pdf

[24] European Energy Review. Smart grid revolution gets underway in Austria. Available from: http://www.europeanenergyreview.eu/index.php?id=740\&id_referer=2767\&id_artikel=2767. 2011

[25] SMART-A. Smart Domestic Appliances Supporting the system Integration of Renewable Energy. A report for the European Commission within the Intelligent Energy Europe Programme. Available from: http://www.smart-a.org/SmartA_Project_Final_Brochure_2009.pdf. 2009

[26] Vasaaet, Capgemini, and Enerdata. Demand Response: A Decisive Breakthrough for Europe; 2008. Available from: http://www.capgemini.com/insights-and-resources/by-publication/demand response_a_decisive_breakthrough_for_europe/

[27] Criqui, P. Prospective Outlook on Long-term Energy Systems. Institute D’Economie et de Politique de L'Energie. Available from: http://webu2.upmf-grenoble.fr/iepe/textes/POLES8p 01 .pdf. 2001.

[28] ERGEG. Status Review on Regulatory Aspects of Smart Metering (Electricity and Gas). May 2009. European Regulators Group for Electricity and Gas. Report E09-RMF-17-03. Available from: http://energypapers.com/node/2508.

[29] Owen, G, Ward, J. Smart Meters in Great Britain: The Next Steps? Sustainability First. 2007. Available at http://www.sustainabilityfirst.org.uk.

[30] Torriti, J, Hassan, M.G, Leach M. Demand response experience in Europe: Policies, programmes and implementation. Energy 2009; 35(4); 1575-1583.

[31] Kim J.H, Shcherbakova A. Common failures of demand response. Energy 2011; 36(2); 873-880.

[32] Golz, S. Smart Metering and feedback systems: Suitable instruments to increase sustainable energy consumption? TRANSPOSE Midterm Conference. November 2009. Available from: http://www.intelliekon.de/ergebnisse/downloads/kommt-der-pull-von-smart-metering-vom-markt/ view

[33] European Commission. Directive 2006/32/EC of the European Parliament and of the council of 5 April 2006 on Energy End-Use Efficiency and Energy Services and Repealing Council Directive 93/76/EEC; 2006.

[34] ESMA. Smart Metering Guide - Energy Saving and the Customer. Edition 2010. Available from: http://www.esma-home.eu/UserFiles/file/downloads/Final_reports/ESMA_WP4D16_ESMA\%20 Guide_2009_Final.pdf

[35] Gleerup M, Larsen A, Leth-Petersen S, Togeby M. The Effect of Feedback by Text Message (SMS) and Email on Household Electricity Consumption: Experimental Evidence. Energy Journal 2010; 31:113-157.

[36] Greening, L.A. Demand response resources: Who is responsible for implementation in a deregulated market? Energy 2010; 35(4); 1518-1525.

[37] Faruqui, A, Hajos, A, Hledik, R.M, Newell, S.A. Fostering economic demand response in the Midwest ISO. Energy 2010; 35(4); 1544-1552.

[38] Eurelectric. Electricity Companies' Activities on End-Use Energy Efficiency. Energy Efficiency Working Group; 2007. Available from: http://www2.eurelectric.org/Content/Default.asp?

[39] European Commission. Communication from the Commission to the Council and the European Parliament: 7 Measures for 2 Million new EU Jobs. A Low Carbon Eco Efficient and Cleaner Economy for European Citizens; 2009.

\section{List of figure and table captions}

Figure 1: Analytical framework 
Figure 2: Modeling of real-time pricing

Figure 3: Impact of time-varying prices on load curve - RTP

Table 1: Guidelines for the implementation of smart meter related sets of actions

Table 2: Peak load reduction estimates for different sets of DR actions, system and consumer types

Table 3: Electricity savings estimates for different sets of DR actions, system and consumer types

Table 4: Size of demand response in different EU countries

Table 5: Global electricity savings and peak load reduction for the residential sector 